\title{
CONCEPÇÕES JAPONESAS DO ROMANCE DO EU
}

Neide Hissae Nagae

RESUMO: Veremos, aqui, as origens do Romance do Eu, e as mudanças que se processaram na sua interpretação. $O$ termo Romance Introspectivo, inicialmente utilizado por Kume Masao para melhor explicar o Romance do Eu, recebe nova interpretação com Itô Sei e Hirano Ken, gerando uma divisão entre os termos.

ABSTRACT: This study shows the origins of the I novel and its differents interpretation. The term Contemplative Novel, first introduced by Kume Masao to better elucidate de I novel, gains a new interpretation with Itô Sei and Hirano Ken, resulting in a division of the terms.

PALAVRAS-CHAVE: Romance do Eu, Romance Contemplativo, "Ich Roman", origens, mudança de interpretação.

KEYWORDS: I Novel, Contemplative Novel, "Ich Roman", origin of the I Novel, change in the interpretation.

O termo Watakushi Shôsetsu ou Shi Shôsetsu, aqui traduzido para Romance do Eu, começa a aparecer no Círculo Literário Japonês do final de 1920 ao início de 1921 .

No princípio, esse termo possuía um sentido depreciativo de romance simplório e também uma conotação discriminativa e pejorativa. A falta de elaboração estrutural e os problemas ligados à ficcionalidade dessas obras, surgidas após a primeira metade de 1920, que utilizavam personagens com nomes de pessoas reais ou falavam sobre assuntos pessoais, é apontada pela nota explicativa do livro Romance do $E u^{\prime}$ como razão desses sentidos depreciativos.

1. Watakushi Shôsetsu, Nihon bungaku kenkyû shiryô sôsho. 
Mais tarde, é utilizado amplamente na Literatura Moderna Japonesa e não ficou restrito a mero termo literário de uma época. Passou, inclusive, a ser utilizado para designar um tipo característico de romance, antes e após a Segunda Guerra Mundial.

É bem ilustrativa a frase de Katsuyama Issao": "Penso no Romance do Eu como o rabo de uma lagartixa que está sempre a se regenerar"

\section{Estudos do Final da Era Taishô (1912-1926) ao Início da Era Shôwa (1926-1987)}

Entre 1924 e 1925, diversos estudos sobre o Romance do Eu geram discussões em todo círculo literário.

A explicação do livro Romance do Eu, indica alguns desses estudos, fornecendo um breve resumo: o estudo de Nakamura Murao (1886-1943) "Honkaku Shôsetsu to Shinkyo Shôsetsu" (Romance Autêntico e Romance Introspectivo), Shin shôsetsu, 01/ 1924 utiliza o termo Romance Introspectivo ao invés de Romance do Eu e o compara com romances como Anna Karenina de Tolstói, concluindo que o Romance Introspectivo é uma literatura peculiarmente japonesa, que lembra o lirismo das poesias e dos haicais; o estudo de Ikuta Chôkô, (1882-1936) Nichijô seikatsu o henchô suru akukeikô (Uma Tendência que Superestima o Cotidiano), Shinchô, 07/ 1924 vai ao encontro do estudo de Nakamura quando ele diz tratar-se de uma péssima corrente que invade o mundo da Literatura, e propõe a sua desvalorização no meio literário. Em contrapartida, Kume Masao (1891-1961) em Watakushi shôsetsu to Shinkyô Shôsetsu (Romance do Eu e Romance Introspectivo), Bungei Kôza, 1/1925 avalia o Romance do Eu como a base, o caminho verdadeiro, a essência, no verdadeiro sentido da arte em prosa. Diz tratar-se de um "gênero" movido por interesses não momentâneos, que não se limita à tendência literária de uma época. Uno Kôji (1891-1961) em "Watakushi shôsetsu" shiken (Minha Visão sobre o "Romance do Eu"), Shinchô, 10/1925, busca as origens do "Romance do Eu" nas obras de Mushanokoji Saneatsu (1885-1976) da corrente literária Shirakaba ${ }^{3}$, e, embora simpatizante da concepção de Nakamura Murao, observa que os japoneses são ricos em características do Romance Introspectivo e sua postura é a de reconhecer o Romance do Eu como produto peculiar do círculo literário japonês. Satô Haruo (18921964) em Shinkyô shôsetsu to Honkaku shôsetsu (Romance Introspectivo e Romance Autêntico) Chuô Kôron, 03/1928, diz que o Romance do Eu faz parte do Romance autêntico, ou seja, os romances propriamente ditos, e não o considera "um método desonesto encontrado por alguns escritores, ao final de uma vida de ociosidade", achandoo tão interessante quanto uma poesia em prosa. A seu ver, o motivo para a produção do Romance Introspectivo era condicionado pela concepção de autor dada pela sociedade: serem reconhecidos como autor entre os vinte e cinco e trinta anos, em sua grande

2. Revista Kokubungaku, vol. 11, n. 3, março de 1966, p. 32.

3. Movimento literário centrado na revista Shirakaba que vai de 1910/1911 a 1924, formada por escritores como Mushanokoji Saneatsu e Shiga Naoya que receberam influência de Tostói e defendiam o humanismo. 
maioria, após passar apenas pela experiência estudantil e amorosa e exercitar a imaginação poética e a análise psicológica sobre si mesmos.

Asami Fukashi (1899-) em "Watakushi shôsetsu" kaishaku no hensen (Mudanças na Interpretação do "Romance do Eu"), Kokubungaku, kaishaku to kyôzai no kenkyû, vol. 11, n.3 de 03/1966, parte do pressuposto de que o problema do Romance do Eu foi encarado com seriedade a partir do texto Romance do Eu e Romance Introspectivo de Kume Masao publicado na revista Bungei Kôza de janeiro e fevereiro de 1925.

Nesse texto, Kume coloca que o termo Romance Instrospectivo, alvo das discussões que aconteciam no círculo literário japonês, fora por ele utilizado provisoriamente para denominar o Romance do Eu, inspirando-se no termo empregado pelos haicaístas, e explica:

Em poucas palavras, é o romance em que, o autor faz com que o objeto retratado emerja tal qual a realidade, ou melhor, coloca-o tal qual a realidade, e, ao mesmo tempo, em termos simples, tenta expressar o sentimento do momento, e, em termos mais complicados, tenta expressar principalmente as impressões sobre a visão de vida que o autor possui diante do que está retratando.

Acha improvável que apareça uma definição sobre qual visão é a melhor, mas defende que "O Romance do Eu é a base, o caminho verdadeiro e a essência da Literatura ou, num plano mais restrito, da arte em prosa". Como justificativa, Kume coloca a questão da confiança na veracidade do que está escrito. Menciona o Ich Roman alemão que, traduzido, corresponderia a Romance do $\mathrm{Eu}$, mas que diria respeito às obras onde o protagonista fala na primeira pessoa $I c h$, ou seja, Eu. Descarta-o como Romance do $\mathrm{Eu}$, pois a personagem principal poderia ser qualquer um, ser animado ou inanimado, que não fosse o próprio autor, e coloca o sentido que pretende atribuir ao Romance do Eu: "um romance onde o autor se revela por inteiro", mas nem por isso trata-se de autobiografia ou confissão. A título de exemplo, coloca que a Ressurreição de Tolstói, apesar dos elementos artísticos, não é um Romance do Eu e nem as Confissões de Rousseau, que possui alguns aspectos de romance, enquanto que Plaidoyer d'um fou de Strindberg, seria claramente um Romance do Eu nos moldes defendidos por ele.

Segundo Asami Fukashi, para Kume, Romance do Eu era equivalente a Romance Introspectivo, e a base da arte estava no "eu" e na sua expressão sincera, sem disfarces. É uma negação da ficção como forma do Romance. Nesse sentido, tratava-se da reconstituição de uma vida. E só aquele que realmente estava consciente do seu "eu" interior e conseguia expressá-lo no papel, "tal qual a realidade". poderia ser chamado de artista. "Tal qual a realidade", nesse caso, não significava um retrato da forma como a realidade é. Não devia haver distorções, exagero ou falta, mas também não deveria apresentar o estado bruto, apresentando todo um processo de criação do Romance do Eu. Havia uma necessidade de condensação. Condensar o "eu" fundi-lo, filtrá-lo, concentrá-lo, misturá-lo e fazê-lo renascer, e necessidade também de uma introspecção sólida e desprovida de erro. Foi por isso que Kume deu, ao Romance do Eu, o nome de Romance Introspectivo.

Akutagawa Ryûnosuke (1892-1927), em "Watakushi" shôsetsu ron shôken (Breve Opinião sobre a Teoria do Romance do "Eu"), de 10/1925 tenta discutir a respeito da 
afirmação de Kume de que "o Romance do "Eu" é o verdadeiro caminho da arte em prosa. Para ele, a falha dessa afirmação está na criação de um lugar utópico chamado verdadeiro caminho da arte em prosa, e não no fato de ter colocado o Romance do "Eu"como o verdadeiro caminho da arte em prosa. Não se opõe ao Romance do "Eu" mas à essa visão sobre o Romance do "Eu" Defende que, na essência, ele não difere nem um pouco dos romances ditos autênticos e afirma que, se existe algum motivo para que ele seja o que é, esse motivo deve existir em algum fato real que vê um acontecimento dentro do Romance do "Eu" como um acontecimento da vida do autor. O Romance do "Eu" seria um romance com uma garantia sobre a veracidade de seu conteúdo. Isso parece fazer sentido em termos de arte literária porque se pensa que a literatura tem uma relação mais profunda com a moral e a virtude do que as outras formas de arte, mas segundo Akutagawa, a arte literária não difere nem um pouco das demais, nada tendo a ver com esses valores, e, ultrapassando essa preocupação com a moral e a virtude, ela não possui nenhuma restrição, é livre como o vento. Com isso, ele invalida a veracidade e a sinceridade que o autor deve colocar na obra e diz que, se é que existe um caminho verdadeiro da arte literária, provavelmente ela estaria no alto de uma montanha chamada obra-prima.

Essas considerações do final dos anos de 1925 ao início de 1926, (final da Era Taishô ao início da Era Shôwa) vão servir de ponto de partida para muitas outras surgidas posteriormente.

A partir de 1926, com a dita Literatura do Proletariado liderando momentaneamente o círculo literário, o Romance do Eu assume uma posição secundária.

\section{Novas Concepções}

Por volta de 1935 a teoria do Romance do Eu passa a ser repensada em termos comparativos com a Literatura Moderna européia.

Kobayashi Hideo (1902-1983), em Watakushi shôsetsu ron (Teoria do Romance do Eu) Keizai Ôrai maio a agosto de 1935, parte do Naturalismo francês até chegar em André Gide em paralelo com o Naturalismo japonês até o "Romance do Eu" para estudar as formas de expressões do "eu" peculiar da literatura moderna do Japão, o "eu" dos autores da Era Taishô e o "eu" dos autores da Era Shôwa, em meio à decadência da literatura marxista e a divulgação da obra Junsui shôsetsu ron (Teoria do Romance Puro) de Yokomitsu Riichi (1898-1947), em abril de 1935, na revista Bungei Shunjû, e também discutir a respeito das tradições em termos de vivência social dos autores japoneses e o "eu" Para Kobayashi, o Romance do Eu é conseqüência não apenas de uma natureza subjetiva do japonês, mas também de uma sociedade sem estruturas para criar um novo pensamento do tipo europeu, e de escritores que não sentiam necessidade de se envolver com pensamentos novos, como aconteceu com os jovens escritores dos meados do século IX na Rússia.

Também em 1935, Kume Masao, em Jun Bungaku yogi setsu (Teses sobre Habilidades Extras na Literatura Pura), coloca a questão do Romance do Eu como uma habilidade extra de uma pessoa que escreve seu estado de espírito sem ser forçado por ninguém, como um ser que possui uma razão de ser, o que é também o seu conceito 
sobre a chamada Literatura Pura. Não se trata de um passa tempo e nem de uma profissão, mas de uma vivência que vai além da vivência feita para a "salvação de uma vida levada a sério" Como exemplos de habilidades extras da Literatura Pura, são citadas, entre outras, as obras de Shiga Naoya (1883-1971); Ukigumo ${ }^{4}$ como habilidade extra de uma vida inteira de um homem; Shosei katagi ${ }^{5}$ como habilidade extra de um professor da Universidade Waseda e Neko e Bocchan ${ }^{7}$ como habilidade extra de um professor da Universidade Imperial.

Na obra intitulada Fûzoku Shôsetsuron (Teoria do Romance de Costumes), de junho de 1950, Nakamura Mitsuo (1911-1963) também pensa o Romance do Eu japonês, de forma ampla em comparação com as obras de Flaubert, Sthendal, Zola e outros autores da Literatura européia. Pesquisa desde os problemas relativos à origem do Romance do Eu até às circunstâncias que o levaram a possuir características peculiares. Diz que a visão colocada por Kume no final da Era Taishô, ou seja, que "O Romance do Eu é, a base, no sentido autêntico, o caminho verdadeiro e a essência da Literatura e, caso se ache amplo demais, da arte em prosa" não é uma opinião pessoal mas um pensamento comum no meio literário. Nakamura explica que $F_{u t o n}^{8}$, serviu de molde para muitas obras excelentes da Era Taishô, independentemente do pensamento do autor ou da corrente literária a que ele pertencia. Mas, que Futon possuía algumas falhas adquiridas no processo de sua formação. Uma delas diz respeito à grande idéia de Katai em se imaginar como personagem dos romances estrangeiros ou das peças teatrais japonesas chamadas de gikyoku, experimentar os motivos das obras e transformar a figura do autor que faz esse tipo de encenação na personagem principal do romance, pois essa era uma forma fácil e confiável para se adaptar à moderna Literatura Ocidental, e lhe atribuía a qualificação de representante de uma nova época. $O$ autor escolhia um romance mais adequado à sua representação individual, e, tendo-o como palco, conseguia a expressão individual e ao mesmo tempo, encarnar um novo pensamento estrangeiro. Nesse sentido, a forma do Romance do Eu era um dispositivo fácil e prático para a implantação da Literatura estrangeira. Isso, é claro, não significa que todas os Romances do Eu tenham sido feitos como Futon.

Após a guerra, a teoria do Romance do Eu ganha um novo desenvolvimento com Shôsetsu no Hôhô (Formas do Romance) (12/1948) de Itô Sei(1905-1969). Trata-se de uma elucidação peculiar da Literatura Japonesa sobre o Romance do Eu. Itô acredita que o avanço da imprensa gera uma mudança de apresentação da forma literária, pois, tanto o fazer literário da parte do autor, como a recepção literária por parte do leitor passam a ser atos solitários, e o autor produz a obra numa sala secreta, onde pode revelar a sua voz interior da forma mais autêntica. Ee é o que fazem os autores do Romance do Eu, no início, limitados aos círculos literários, onde se é permitido revelar tudo francamente e onde se valoriza a integridade e a honestidade nas obras literárias em

4. Obra de 1887 do autor Futabatei Shimei (1864-1909).

5. Obra de 1885 de Tsuboichi Shôyô (1859-1935).

6. Obra de 1905 de Natsume Sôseki (1867-1916).

7. Obra de 1906 de Natsume Sôseki.

8. Obra de Tayama Katai (1871-1930) considerada por muitos estudiosos como primeira obra do Romance do Eu. 
busca do sentido da vida humana. Ao colocar suas experiências no papel é como se eles fizessem uma dissecação do ser humano, expondo o lado mais obscuro da sua própria vida e também a de seus familiares ou amigos mas que depois, não há mais como voltar atrás. Nesse sentido, a obra ganhava em termos de comover o leitor mas o autor chegava à destruição da própria vida. As obras que seguiam esse percurso foram por ele chamadas de modelo destrutivo e os seus autores, de "escravos fugitivos", já que se isolavam da sociedade e viviam no e para o círculo literário. Por outro lado, os autores que ele denominou de "gentlemen disfarçados" por viverem na sociedade e com ela manterem uma relação harmoniosa, escreveram obras assumindo uma posição de seres sociais, limitando-se a manter uma certa distância com os fatos comprometedores. Tais obras foram denominadas de modelo harmonioso. Nelas, pensava-se na vida como algo mais alegre e equilibrado, onde a boa intenção dos homens viria a dar frutos.

Hirano Ken (1907-1978), seguindo a linha de Itô Sei, coloca que o Romance do Eu e o Romance Introspectivo são vistos com a característica de abordar temas do cotidiano mas que no fundo, ambos têm em comum, um tema que não é nada cotidiano, ou seja a sensação de crise ou risco de vida e o desejo de salvação ou superação. Se no Romance do Eu, essa crise se manifesta ligada a uma esfera familiar na forma de uma revelação do próprio estado da crise, buscando a salvação e a superação na arte, o Romance Introspectivo é uma palavra final sobre a superação da crise, na tentativa de chegar a uma sensação de equilíbrio na busca pela salvação e superação na própria vida real. Nesse sentido, Hirano associa o Romance do Eu ao modelo destrutivo, e o Romance Introspectivo ao modelo harmonioso. O primeiro é a literatura dos arruinados e dos que abandonaram a vida real, e o segundo é a literatura dos apaziguadores e dos que mantêm a vida real.

Foi a partir desse desdobramento que o Romance Introspectivo ganhou uma interpretação completamente diferente, e o Romance do Eu passou a ter uma interpretação dividida claramente em três:

1. Romance do $E u$-É a "literatura destrutiva"que revela a própria crise, sem uma certeza de resolução. Ou seja, basea-se no estranhamento entre o mundo exterior e o ego, e busca na arte, a salvação para a crise existencial oriunda da ignorância sobre 0 que fazer com a vida ou da gravidade do pecado. Pressupõe também a aspiração literária como pecado original, constituindo, a literatura dos alienados do mundo real do tipo destrutivo. É a linhagem que vai de Chikamatsu Shûkô (1876-1944) a Dazai Osamu (1909-1948), passando por Kamura Isota (1897-1933).

2. Romance Introspectivo - Em contrapartida ao Romance do Eu, é a Literatura de superação da crise, a Literatura da salvação. Por conseguinte, busca, na vida real, a salvação para a crise existencial. Ou seja, é a literatura dos que apreendem a vida real e teve origem na literatura da Corrente Shirakaba idealista. É a literatura que vai de Shiga Naoya, passa por Takii Kôsaku (1894- ) e chega até Ozaki Kazuo (1899-1983), e entre as melhores obras, há casos em que se estabelecem sensações sobre o destino ou sobre a vida ou a morte, acrescidas de um caráter ideológico.

3. Ich Roman-É um termo alemão que, traduzido literalmente, significa Romance do Eu, mas tem uma natureza completamente diversa. Qualquer obra escrita em primeira 
pessoa é chamada de Ich Roman. Os chamados Romance do Eu, em moda recentemente, são quase todos desse tipo. Principalmente os romances que estão em situação intermediária. $\mathrm{O}$ "eu" nada tem a ver com a obra e desempenha apenas papel de narrador.

Atualmente, herdando a teoria de Itô e Hirano, teóricos como Takahashi Hideo (1930- ) e Matsubara Shin'ichi (1940 ) têm explorado novos sentidos para o Romance do Eu.

\section{Bibliografia}

AKUTAGAWA, Ryûnosuke. "Watakushi"shôsetsu ron shôken", in Nihon gendai bungaku zenshû 56 Akutagawa Ryûnosuke shû. Kôdansha, ed. rev. 1980, pp. 446-448.

ASAMI, Fukashi. "Watakushi Shôsetsu kaishaku no hensen" Kokubungaku, kaishaku to kyôzai no kenkyû, vol. 11, n. 3, 1966, pp. 10-15.

HIRANO, Ken. "Watakushi shôsetsu no niritsu haihan", Nihon gendai bungaku zenshû 97 Kôdansha, ed. rev. 1980, pp.7-20.

ITô, Sei. Shôsetsu no hôhô. Kawade shobô, 1951. Shimin Bunko 27. Bungaku Nyûmon. 1986, Kôbunsha, pp. 92-162.

KATSUYAMA, Isao. "Taishô-ki ni okeru watakushi shôsetsu no keifu", Kokubungaku, kaishaku to kyôzai no kenkyû, vol. 11, n. 3, 1966, pp. 32-37.

KoBAYASHI, Hideo. "Watakushi shôsetsu ron", in Kobayashi Hideo Zenshû, vol. III, Shinchô, 1968, pp. 119-145.

KuME, Masao. "Watakushi shôsetsu to Shinkyô shôsetsu", in Nihon gendai bungaku zenshû 57. Kikuchi Hiroshi/Kume Masao shû. Kôdansha, ed. rev. 1980, pp. 406-411.

"Jun bungaku yogi setsu" idem, pp. 411-413.

SEKIGUCHI, Yasuyoshi. "Kaisetsu", in Yamazaki, Makoto. Watakushi shôsetsu. Tóquio, Yûseitô, 1983, pp. 299-302.

UsuI, Yoshimi. "Shinkyô Shôsetsu to Tsûzoku Shôsetsu" Taishô Bungakushi. Chikuma Sôsho 7, 1963, pp. 198-210.

ODAGIRI, Susumu. Nihon Kindai Bungaku Daijiten, 1984, Kôdansha.

Neide Hissae Nagae Curso de Pós-Graduação do Departamento de Línguas Orientais da FFLCH da USP Área de concentração: Lingua, Literatura e Cultura Japonesa. R. Pedro Gabriel Sabatini, 86 - SBC. 09781-340 - São Paulo 